\title{
Nanoemulsion of Virgin Rapeseed and Sesame Oil improve Oxidation Stability and Sensoric acceptability of Vacuum Packed Fish Fillets
}

Iqra Anwer ( $\boldsymbol{D}$ iqra.anwer@uvas.edu.pk)

University of Veterinary and Animal Sciences

Farzana Abbas

University of Veterinary and Animal Sciences

Muhammad Hafeez-ur-Rehman

University of Veterinary and Animal Sciences

Muhammad Nadeem

University of Veterinary and Animal Sciences

Maryyum Khalil

University of Veterinary and Animal Sciences

Mahrukh Butt

Chung-Ang University

Muhammad Inayat

University of Veterinary and Animal Sciences

\section{Research Article}

Keywords: Nanoemulsion, Channa marulius, Rapeseed oil, Sesame oil, antioxidants, lipid oxidation, vacuum packing and sensory evaluation.

Posted Date: March 12th, 2021

DOI: https://doi.org/10.21203/rs.3.rs-152180/v1

License: (c) (i) This work is licensed under a Creative Commons Attribution 4.0 International License.

Read Full License 


\section{Abstract}

Background: Fish contains high polyunsaturated fatty acids and has good healthy biological values, so it is considered a vital ingredient in the human diet. Antioxidants play an essential role in the food industry due to their help breaking down the oxidation process. The consumer demands fresh refrigerated foods that extend shelf life without changing taste. By using oil and vacuum packaging techniques, considerable research has been conducted to preserve and extend the shelf life of Channa marulius fillets. Since rapeseed oil and sesame oil are considered good sources of antioxidants, their role in preserving and extending the shelf life of Channa marulius fillets is limited.

Methods: Channa marulius fish fillets weighing 4-5 kg each were obtained from the market. The fillets were washed and divided into 5 groups using different concentrations of sesame oil (S.O) and rapeseed oil (R.O) nanoemulsion i.e., Control (C) without treatment, T1 (S.0 20\%), T2 (S.0 25\%), T3 (R.0 20\%) and T4 (R.O 25\%). The fillets were soaked in nanoemulsion for 30 minutes and packed with a vacuum packing machine before storing at $-40^{\circ} \mathrm{C}$. After an interval of $0,4,7$, and 15 days the oxidative stability, antioxidant activity and sensory evaluation determined of each treatment were determined.

Result: Compared with the control group, the free fatty acid (FFA) levels and peroxide values (PV) values were lower in the treated groups. Lipid oxidation increased over time in the control group due to lipid oxidation. Total phenolic content (TPC), total flavonoid content (TFC) and antioxidant activity of the fillets decreased due to the nanoemulsion. Oxidative stability fluctuated and increased with storage time because of more fatty acid hydrolysis. The reduction was noted in the antioxidant property because it hampered the oxidation stability. Channa marulius' sensory evaluation revealed that nanoemulsion and vacuum packaging had a higher sensory score than the control group.

Conclusion: The role of rapeseed and sesame oil as natural antioxidants was investigated to preserve and extend the shelf life of Channa marulius fillets. The use of nanoemulsions by using sesame oil and rapeseed oil reduced the oxidation stability and enhance the antioxidant activity of Channa marulius fillets. Among the oils, it can be concluded that sesame oil can be recommended for nanoemulsion as a good preservative for fish fillets.

\section{Background}

Today, fish provides most animal protein for more than 1 billion poor people daily. Fish contains the most important nutrients for children's physical development and omega three fatty acids, which are also part of energy nutrition. Fish have importance in the food industry and added to the human diet as a big protein source, consisting of essential nutrients and intended use for balancing the nutritional profile [1]. In freshwater aquaculture, Channa marulius is gaining importance in South Asia, Pakistan. India, China, and Thailand. Channa marulius is well-liked among fish farmers due to its hardiness, fast growth, adaptability to artificial feed and high market price, while among consumers due to its high nutritional value, the physical appearance of flesh and tempting taste. [2,3]. Emulsions are an interesting and well- 
used method for oils' stability in a liquid phase. The nanoemulsion oil in water $(\mathrm{O} / \mathrm{W})$ emulsion is a multifaceted method for stabilizing the liquid emulsion. The emulsion remains stable due to a solid structure. [4]. The properties of solidifying emulsions are similar to traditional emulsions formed using animal fat. Animal fat is used in the emulsion for the improvement of healthier products. On the other hand, in our knowledge, an oil droplet size depends on the quantity of oil used in emulsion e.g. (20\% of oil) used as a stabilizing lipid model. [5, 6].

In the food industry, antioxidant plays an essential role in inhibiting microbial activity and delaying the oxidation process. The naturally occurring antioxidant is widely used in aquaculture because it enhances growth performance and prolongs shelf life during processing. The demand for antioxidants in the food industry increases due to consumer belief that natural antioxidant contain the entire nutritional profile that is beneficial for health rather than artificial antioxidants. Natural antioxidants are free radicals of oxidative destruction which act as a biochemical inhibitor. Antioxidants, in which mainly come phenolic content, flavonoid content have been used to prevent oxidation [7]. The artificial antioxidant added in food is the most capable way to decrease rancidity and prolong food storage time [8]. It is also predicted that some antioxidant compounds can control human diseases [9]. Rapeseed oil is globally significant because it contains a high level of unsaturated fatty acid and vitamin $B$. The phenolic compounds present in rapeseed oil are beneficial for health. These phenolic compounds are used to treat many diseases, such as anti-mutagenic, anti-inflammatory, or anti-carcinogenetic activities [10,11]. Naturally occurring antioxidants such as tocopherols, phenolic compounds, carotenoids, or phospholipids are present in rapeseed oil [12].

Lipid oxidation is a significant reason for the quality decline in fish muscles. It produces vinegary taste during manufacturing, packing, delivery, and final food preparation [13]. The oxidation of lipid is abundant in food and meat products; however, the oxidation level is different in different products. The levels of oxidation are mostly low, severely affecting the quality of food products and limiting the shelflife [14]. One approach to decrease the level of lipid oxidation and hindrance the quality loss and sensory attributes are synthetic and natural antioxidants.[15]. Oxidative stability is most important for sensory evaluation for refutation and acceptable for fish after the time interval of storage.[16] Oxidation stability of lipid will lead to loss of micro and macromolecule rancidity.[17] . Fish rancidity is an essential factor that determines fish quality deterioration. The fish rancidity is caused by lipid oxidation during refrigerated and frozen storage.[18]. Fish muscle contains unsaturated fats, heme pigments, and essential sources for that exposure. In fish sensory evaluation, the texture damage is the first attribute by which the fillet lost the fresh flavor (sweet) monitored by the change of odor/flavor (Torrey score 7 out of 10). The storage period is usually determined when microbial growth starts decreasing shelf life and causes pungent odor and flavor. Different processing techniques (salting, smoking and drying) delay the oxidation process and are prone to rancidity [19].

The modern technology of packing method: vigorous and quick packing plays a vital role in food processing and provides the solution to preserve the food for a long time and have no adverse effect on its organoleptic and storage time. Vacuum packaging is a modern technology which establishes for food 
preservation to enhance the shelf life, which works according to change the gas magnitudes in a food surrounding by diminishing oxygen or changing the atmosphere gas inside the packet by a combination of different gases[20]. A vacuum-packaging machine has a role in packing modified packaging. The present study aimed to examine the effect of edibles oil nanoemulsion which are carriers of natural antioxidants used to enhance the shelf-life of food and are capable of hindering or avoiding the rancidity in food due to oxidation.

\section{Methods}

\section{Aims:}

To study the effect of rapeseed \& sesame oil on antioxidant activity. To study the decline in oxidation stability of Vacuum Packaged (Channa marulius) fillets under the frozen condition and enhance the sensory evaluation of fish fillet by immersing in nanoemulsion of virgin rapeseed and sesame oil.

\section{Preparation of nano-emulsions:}

To preparation nanoemulsion develop two-step procedure consisting of oil and water phase was adopted as previously described . [21]Oil and water-based nanoemulsions (O/W) was prepared comprised on oil (rapeseed, sesame) with a concentration of $20 \%, 25 \%$, glycerin (2\%), and a surfactant (gelatin $3 \%$ ). The oil phase components were mixed in the water phase accordingly $(70,75 \%)$. The mixture was homogenized for $10 \mathrm{~min}$ after one hour. The volume of emulsion processed was $1000 \mathrm{ml} .[22]$

\section{Fish fillets Preparation:}

Channa marulius, with an average weight of $4-5 \mathrm{~kg}$, was purchased from the supper market (Lahore). Fish fillets preparation included cutting, gutting, skinning and filleting. The fillets were washed and divided into 5 experimental groups. Four groups were treated with different concentrations of nanoemulsion i.e., T1 (S.O 20\%), T2 (S.O 25\%),T3(R.O 20\%), T4 (R.O 25\%) and control (C) without treatment. The Channa marulius fillets were soaked $(3 / 1, w / v)$ for 30 minutes in the prepared nanoemulsions with different concentrations of rapeseed and sesame oil and immediately vaccum packed in polyamide bags. After the vacuum packing, the filets were stored at $-40{ }^{\circ} \mathrm{C}$ temperature for 0,4 , 7 , and 15 days for further analysis.

\section{Free fatty acids}

FFA were determined by using the titration method [23]. Fifty milliliters of ethanol was titrated against the $0.1 \mathrm{~N}$ solution of $\mathrm{NaOH}$ using 3-4 drops of $1 \%$ phenolphthalein indicator. One gram of sample was added in the flask and again titrated with $0.1 \mathrm{~N}$ solution of $\mathrm{NaOH}$ till the endpoint with pink coloration. The titrant volume was noted and FFA was determined by using the following formula. FFA= Volume used in burette $\times 0.1 \times 282 \times 100 / 1000 \times$ sample weight

\section{Peroxide value}


In a conical flask 2 gram sample, $1 \mathrm{~mL}$ saturated $\mathrm{KI}$ and $30 \mathrm{~mL}$ of $\mathrm{PV}$ solution were added and kept in the dark for one minute. After 1 minute, $30 \mathrm{ml}$ of distilled water was added along the flask walls. One milliliter of the starch solution was added to the mixture and titrated sodium thiosulphate solution till the endpoint (white color). The burette reading was used for peroxide calculation by using the following formula [23].

PV $=$ Volume used $\times$ Normality used $\times 1000 /$ sample weight

\section{Total Flavonoid Content:}

The total flavonoid content of Channa marulius fillets was determined by spectrophotometric examination using rutin as standard. In a test tube fish extract $(0.1 \mathrm{ml})$ and $0.2 \mathrm{ml}$ solution of $5 \% \mathrm{NaNO}_{3}$ were mixed. After five minutes, $0.2 \mathrm{ml}$ of $\mathrm{AlCl}_{3}$ and $1 \mathrm{ml}$ of $\mathrm{NaOH}$ (1 Molar) were added and the tube was incubated at room temperature for $15 \mathrm{~min}$. Samples and standards was measured at $510 \mathrm{~nm}$ absorbance on a spectrophotometer. Total flavonoid content were reported as $\mathrm{mg} \mathrm{RE} / \mathrm{g}$. followed by flavonoid derivatives [24]

\section{Total phenol content:}

The phenol contents in Channa marulius fillets were determined using the reagent folin ciocalteu [25]. One gram of the sample was mixed with $2.5 \mathrm{ml}$ folin ciocalteu $(0.2 \mathrm{M})$ and $2 \mathrm{ml}$ sodium carbonate $\left(\mathrm{Na}_{2} \mathrm{CO}_{3}\right.$ $7.5 \%)$ in a test tube The cyanogenic contents in extract samples were estimated by alkaline titration according to the method outlined in AOAC [26] and allowed to rest in the dark at $22-24^{\circ} \mathrm{C}$ for 10 minutes. The absorbance of the sample and standard were measured at $765 \mathrm{~nm}$. Gallic acid was used as a standard. The amount of total contents in the sample were determined as mg GAE/g. [27].

\section{Total Antioxidant Activity:}

Total antioxidant activity of Channa marulius fillets was determined using ascorbic acid as standard. In a test tube, 0.3 gram of fish filet was mixed with $3 \mathrm{ml}$ of $0.6 \mathrm{M}$ sulfuric acid. After adding $28 \mathrm{mM}$ sodium phosphate and $4 \mathrm{mM}$ ammonium molybdate solutions, the test tube was incubated at $85^{\circ} \mathrm{C}$ for 90 minutes and absorbance was recorded at $695 \mathrm{~nm}$ through a spectrophotometer. Total antioxidant activity was expressed as mg Ascorbic Acid per gram. And followed by thE Nabasree method [28].

\section{Sensory evaluation:}

Sensory evaluation was conduct by 8 panelists in the sensory evaluation lab in the central lab complex UVAS Ravi Campus Pattoki.Each judge provided written Performa for sensoric evaluation. The panelists were provided informative instructions and brief definitions of attributes such as color, flavor and overall acceptability. Proficient and unexperienced evaluators carried out the sensory analysis of channa marulis fillets according to the instructions given by Meilgaard [29]. They received a set of samples in a randomized order. The fillets were presented at room temperature served in white dishes. The various sensory attributes were analyzed: color, odor, taste, texture, and general acceptability. The panelists were 
provided a rank to judge the sensory properties according to sensory score 1 to 9 (extremely dislike, dislike, dislike moderately, dislike slightly, neither like nor dislike, like slightly, like moderately, like very much, extremely like) followed by Codex Guidelines. [30] sensoric analysis was performed at different storage intervals for experimental treatments.

\section{Statistical Analysis:}

Statistical analysis of the experiment was done by using SAS 9.1 version statistical package. The statistical data was analyzed in two-way analysis of variance. Means of treatment compared by Duncan multiple range tests. $(P<0.05)$

\section{Results}

In the present study, vegetable oil (rapeseed and sesame) has been used due to natural antioxidant and low price. Oxidation and antioxidant activities were monitored for 15 days using different vegetable oil concentrations. The vegetable oil increase antioxidant activity that hindered the oxidative stability of vacuum packed fillets which help in storage for a long period. Generally, the fillets' quality was also affected by using sesame and rapeseed oil. However, the use of nanoemulsions based vegetable oils effectively slowed down the microbial activity. It was observed that treated groups have a low oxidation rate than the control group. Among oils, sesame oil groups gave lower PV than the other control group during storage of fish fillets. A particular focus has been attributed to nanoemulsion as it is being explored to natural antioxidants.

\section{Oxidation Marker:}

\section{Free Fatty Acid:}

FFA are created by the hydrolysis of lipid. The level of FFA content was decreased in nanoemulsion treated group. Statistical analysis demonstrated that the highest FFA development was in the control group compared to T4, T3, T2 and T1, respectively Table 1 . These FFA values increased with the storage time; however, a significant difference exists between the two oils and their concentrations as shown in figure 1 . FFA at $20 \%$ concentration (T1) of sesame oil showed the lowest FFA values than the rape seed oil that gradually increases with a period. These findings could be attributed to the effect of phenol compounds present in sesame oil.

\section{Determination of Per Oxide Value:}

The peroxide value (PV) is defined as the amount of lipid oxidation. Table 1 showed the mean values of peroxides in different fish fillets treatments stored at temperature $-40^{\circ} \mathrm{C}$ for 15 days. The Channa marulius fillets were significantly affected $(\mathrm{P}<0.05)$ by forming peroxides. $\mathrm{PV}$ values of the control group were higher than other treatments and gradually increase with the storage period of fillets. PV value 
gradually increase as storage time increase showed in figure1.FFA, PV values were lowest in the T1 and highest in control, supporting sesame oil nanoemulsion as the best ingredient for filet storage.

Table: 1 . Change in Oxidation Markers during the storage period.

\begin{tabular}{|c|c|c|c|c|c|}
\hline Parameters & Treatments & 0 Day & 4Day & 7Day & 15Day \\
\hline \multirow[t]{5}{*}{$\begin{array}{l}\text { Free Fatty Acid (\% } \\
\text { oleic acid) }\end{array}$} & Control & $4.12 \pm 1.3^{\mathrm{a}}$ & $4.89 \pm .67^{\mathrm{a}}$ & $\begin{array}{c}6.02 \pm \\
\pm 1.78^{\mathrm{a}}\end{array}$ & $7.89 \pm 1.6^{\mathrm{a}}$ \\
\hline & T1 & $3.73 \pm .88^{\mathrm{b}}$ & $4.19 \pm .85^{b}$ & $4.89 \pm 0.75^{b}$ & $5.69 \pm .53^{b}$ \\
\hline & T2 & $3.84 \pm .86^{\mathrm{b}}$ & $4.23 \pm .65^{\mathrm{b}}$ & $5.19 \pm 0.66^{b}$ & $5.73 \pm .86^{\mathrm{b}}$ \\
\hline & T3 & $3.91 \pm .87^{b}$ & $4.43 \pm .59^{b}$ & $5.09 \pm 0.72^{\mathrm{b}}$ & $5.93 \pm .85^{\mathrm{b}}$ \\
\hline & $\mathrm{T4}$ & $3.98 \pm .94^{\mathrm{b}}$ & $4.20 \pm .47^{b}$ & $5.29 \pm 0.77^{\mathrm{b}}$ & $6.00 \pm .47^{\mathrm{b}}$ \\
\hline \multirow[t]{5}{*}{$\begin{array}{l}\text { Peroxide value } \\
\text { (meqO2/kg }\end{array}$} & Control & $4.32 \pm .31 \mathrm{a}$ & $5.12 \pm .38 a$ & $5.55 \pm .63 a$ & $6.81 \pm .85 \mathrm{a}$ \\
\hline & T1 & $3.12 \pm .57 \mathrm{bc}$ & $3.53 \pm .33 \mathrm{bc}$ & $4.12 \pm .69 \mathrm{bc}$ & $\begin{array}{l}4.98 \pm \\
.52 \mathrm{bc}\end{array}$ \\
\hline & T2 & $3.18 \pm .73 c$ & $3.68 \pm .63 c$ & $4.00 \pm .31 \mathrm{c}$ & $\begin{array}{c}4.65 \pm \\
.59 c\end{array}$ \\
\hline & T3 & $3.88 \pm 0.51 b c$ & $4.00 \pm .62 \mathrm{bc}$ & $4.66 \pm .63 \mathrm{bc}$ & $\begin{array}{l}5.00 \pm \\
.52 \mathrm{bc}\end{array}$ \\
\hline & $\mathrm{T4}$ & $3.90 \pm .73^{\mathrm{b}}$ & $4.34 \pm .33^{\mathrm{b}}$ & $4.23 \pm .14^{\mathrm{b}}$ & $\begin{array}{c}5.55 \pm \\
.85^{\mathrm{b}}\end{array}$ \\
\hline
\end{tabular}

Oxidation Marker(FFA \& P.V) a-c written as mean and \pm S.D.

\section{Oxidant markers:}

\section{Total phenolic content (mg GAE/g) (TPC)}

The results of total phenolic contents (TPC) evaluation in channa marulius filets are represented in figure 2. The highest TPC were observed in T1 and T2 $(0.94 \pm 4$ and $0.97 \pm 16)$ at day 0 . The lowest values were observed in control followed by the T4 and T3. Thus, the sesame oil showed a higher phenol content level that indicated that this compound has a significant contribution to the antioxidant activity. 
Total flavonoid contents (TFC) results were similar to TPC (Figure 3). The lowest values were determined in the T1 and T2 whereas, T4 showed the highest values followed by the control and T3. The values were directly proportional to the storage time. As the storage time increases, the values for TFC increase and are seen highest at day 15 . Again the sesame oil nanoemulsion proved to be a good preservative.

\section{Total antioxidity activity: TAC (mg ascorbic acid/g)}

Figure 4 representing the TAC values of fish filets stored for different days at $-40{ }^{\circ} \mathrm{C}$. Statistical analysis revealed that there was not any significant difference between the treatment as well as the storage duration. Although the values were lowest in the T4 and highest in the T1, the difference was insignificant.

\section{Sensory Evaluation:}

The sensory evaluation of fish filets using nanoemulsion was done on $0,4,7$, and 15 days of storage (Table 2). Statistical analysis showed that the different sensory attributes scoring decreased with the storage period. As the storage time increased, the colure, texture, and taste were reduced elaborated in figure 5. The control group attains the lowest score whereas T4 gains the highest average scores supporting the rapeseed oil nanoemulsion. All the sensory evaluation attributes support the overall acceptability of fish filets in which nanoemelusion of rapeseed oil was used. Although the sesame oil nanoemulsion also gained a good score but perhaps due to the smell of sesame oil the overall acceptability of fish filets decreased compared to the rapeseed oil nanoemulsion.

In conclusion, it was observed that the nanoemulsion of sesame oil was helpful to reduce oxidation of lipids in the storage filets. Eased the antioxidant activity as compared to the rapeseed oil nanuemulsiuon; however, the overall acceptability was heist for the rapeseed oil nanoemusion. The control group showed poor results for oxidation, antioxidation and the overall acceptability with the lowest score supporting that nanoemulsion of vagetables oil can enhance the shelf life and preserve the original sensory properties of processed food items.

\section{Table 2: Sensory evaluation score of fish flesh against various treatments tested.}




\begin{tabular}{|c|c|c|c|c|c|}
\hline Parameters & Treatment & 0 day & 4day & 7 day & 15 day \\
\hline \multirow[t]{5}{*}{ Color } & Control & $6.51 \pm 0.67^{\mathrm{C}}$ & $5.86 \pm 0.87^{\mathrm{C}}$ & $4.89 \pm 0.76^{\mathrm{c}}$ & $2 \pm 0.50^{\mathrm{C}}$ \\
\hline & $\mathrm{T} 1$ & $7.78 \pm 0.90^{\mathrm{a}}$ & $6.12 \pm 0.40^{\mathrm{a}}$ & $5.59 \pm 0.89^{a}$ & $3.31 \pm 0.29^{\mathrm{a}}$ \\
\hline & $\mathrm{T} 2$ & $7.56 \pm 0.43^{\mathrm{a}}$ & $6.13 \pm 0.34^{\mathrm{a}}$ & $5.43 \pm 0.68^{\mathrm{a}}$ & $3.72 \pm 0.13^{\mathrm{a}}$ \\
\hline & T3 & $8 \pm 0.45^{b}$ & $7.32 \pm 0.55^{b}$ & $6.45 \pm 0.85^{b}$ & $4.45 \pm 0.78^{b}$ \\
\hline & $\mathrm{T} 4$ & $8.52 \pm 0.78^{\mathrm{b}}$ & $7.2 \pm 0.78^{b}$ & $6.65 \pm 0.59^{\mathrm{b}}$ & $4.67 \pm 0.98^{b}$ \\
\hline \multirow[t]{5}{*}{ Odor } & Control & $5 \pm 0.67^{\mathrm{b}}$ & $3 \pm 0.77^{b}$ & $2 \pm 0.89^{b}$ & $2 \pm 0.17^{b}$ \\
\hline & $\mathrm{T} 1$ & $6.78 \pm 0.57^{\mathrm{a}}$ & $6.12 \pm 0.98^{\mathrm{a}}$ & $5.59 \pm 1.3^{\mathrm{a}}$ & $4.32 \pm 0.67^{\mathrm{a}}$ \\
\hline & $\mathrm{T} 2$ & $6.56 \pm 0.37^{\mathrm{a}}$ & $6.34 \pm 0.44^{\mathrm{a}}$ & $5.43 \pm 0.37^{\mathrm{a}}$ & $4.71 \pm 0.90^{\mathrm{a}}$ \\
\hline & T3 & $7 \pm 0.66^{\mathrm{a}}$ & $6.01 \pm 0.78^{\mathrm{a}}$ & $5.45 \pm 0.64^{\mathrm{a}}$ & $4.44 \pm 0.97^{\mathrm{a}}$ \\
\hline & $\mathrm{T} 4$ & $7.51 \pm 0.78^{\mathrm{a}}$ & $6.60 \pm 0.87^{\mathrm{a}}$ & $5.61 \pm 0.55^{\mathrm{a}}$ & $4.67 \pm 0.87^{\mathrm{a}}$ \\
\hline \multirow[t]{5}{*}{ Taste } & Control & $5 \pm 0.89^{\mathrm{c}}$ & $4 \pm 0.18^{\mathrm{c}}$ & $3 \pm 0.14^{\mathrm{c}}$ & $3 \pm 0.19^{c}$ \\
\hline & $\mathrm{T} 1$ & $7.7 \pm 0.12^{\mathrm{b}}$ & $6.65 \pm 0.42^{\mathrm{b}}$ & $5.67 \pm 0.90^{\mathrm{b}}$ & $4.32 \pm 0.56^{b}$ \\
\hline & $\mathrm{T} 2$ & $7.3 \pm 0.22^{b}$ & $6.12 \pm 0.31^{\mathrm{b}}$ & $5.59 \pm 0.88^{b}$ & $4.72 \pm 0.78^{b}$ \\
\hline & $\mathrm{T} 3$ & $8 \pm 0.10^{\mathrm{a}}$ & $7.32 \pm 0.12^{\mathrm{a}}$ & $6.63 \pm 0.22^{\mathrm{a}}$ & $4.43 \pm 0.20^{\mathrm{a}}$ \\
\hline & $\mathrm{T} 4$ & $8.11 \pm 0.12^{\mathrm{a}}$ & $7.23 \pm 0.20^{\mathrm{a}}$ & $6.23 \pm 0.25^{\mathrm{a}}$ & $4.62 \pm 0.02^{\mathrm{a}}$ \\
\hline \multirow[t]{5}{*}{ Texture } & Control & $5 \pm 0.12^{b}$ & $4 \pm 0.12^{\mathrm{b}}$ & $3 \pm 0.12^{\mathrm{b}}$ & $3 \pm 0.12^{\mathrm{b}}$ \\
\hline & $\mathrm{T} 1$ & $7.65 \pm 0.45^{\mathrm{a}}$ & $6.32 \pm 0.55^{\mathrm{a}}$ & $5.51 \pm 0.35^{\mathrm{a}}$ & $4.32 \pm 0.46^{\mathrm{a}}$ \\
\hline & $\mathrm{T} 2$ & $7.39 \pm 0.676^{\mathrm{a}}$ & $6.21 \pm 0.54^{\mathrm{a}}$ & $5.25 \pm 0.99^{\mathrm{a}}$ & $4.73 \pm 0.77^{\mathrm{a}}$ \\
\hline & T3 & $7 \pm 0.77^{\mathrm{a}}$ & $7.53 \pm 0.98^{\mathrm{a}}$ & $6.45 \pm 0.55^{\mathrm{a}}$ & $4.61 \pm 0.97^{\mathrm{a}}$ \\
\hline & $\mathrm{T} 4$ & $7.71 \pm 0.20^{\mathrm{a}}$ & $7.23 \pm 0.35^{\mathrm{a}}$ & $6.65 \pm 0.98^{\mathrm{a}}$ & $4.41 \pm 0.75^{\mathrm{a}}$ \\
\hline \multirow[t]{5}{*}{ General acceptability } & Control & $6 \pm 0.65 c$ & $5 \pm 0.65 c$ & $3 \pm 0.65 c$ & $2 \pm 0.65 c$ \\
\hline & $\mathrm{T} 1$ & $6.67 \pm 0.33^{b}$ & $6.12 \pm 0.12^{b}$ & $5.06 \pm 0.09^{b}$ & $4 \pm 0.03^{\mathrm{b}}$ \\
\hline & $\mathrm{T} 2$ & $7.71 \pm 0.19^{b}$ & $6.21 \pm 0.32^{\mathrm{b}}$ & $5.34 \pm 0.33^{b}$ & $4 \pm 0.15^{b}$ \\
\hline & $\mathrm{T} 3$ & $8 \pm 0.33^{\mathrm{a}}$ & $7.32 \pm 0.34^{\mathrm{a}}$ & $6.23 \pm 0.29^{\mathrm{a}}$ & $5.34 \pm 0.23^{\mathrm{a}}$ \\
\hline & $\mathrm{T} 4$ & $8.12 \pm 0.90^{\mathrm{a}}$ & $7.42 \pm 0.12^{\mathrm{a}}$ & $6.34 \pm 0.14^{\mathrm{a}}$ & $5.62 \pm 0.12^{\mathrm{a}}$ \\
\hline
\end{tabular}

\section{Discussion}

Oxidation Marker:

Recently, there has been growing interest in producing nanoemulsions using low-energy means. They have been used in food and beverage industries for specific applications due to their unique 
physicochemical and functional properties like encapsulation efficiency, low turbidity, high bioavailability and high physical stability. In our experiment, we used vegetable oil emulsion for the fish filet preservation and the results obtained were hopeful. The mean values of oxidation, antioxidation and sensory evaluation of fish fillets stored at $-40^{\circ} \mathrm{C}$ for different days favored our hypothesis. Our study showed that both oils significantly increased FFA contents during storage time. This increase of FFA values in fish fillets was found parallel to the studied of [31]. The same trend was reported during fish fillet storage using nanoemulsion products [32]. FFA contents in fish increased during the storage period. FFA contents of Channa marulius samples increased day by day, but less variation was seen in treated group T1, T2, T3 and T4. Fluctuations take place in all treatments of FFA. At the end of storage, the lowest FFA levels were found in the treated group with nanoemulsion of sesame oil. This effect was due to the phenolic compounds of sesame. The present study result is similar to [33], who found that sea bream and sea bass fillets treated with nanoemulsion using sunflower oil lower the FFA value than the control group [34]. The result was also similar to the present study as he concluded that the initial level of fee fatty acid was low, but as storage time of fillets was increased, the value of free fatty acid was also increased. In nanoemulsion FFA is a strong oxidation marker, FFA is main factor of lipid oxidation [35][36] found that the oxidative stability of emulsions is strongly linked to both the concentration and type of free fatty acids present. Our result is opposite to the [37][38], the used plant and herbs extract effect on lipid oxidation development in anchovy stored under refrigeration. The plant extract decreases the mechanism of lipid oxidation in anchovy fish. The acceptable limit for FFA is $15 \mathrm{mg} / \mathrm{g}$ in the present study; the FFA remained acceptable limits throughout the storage period.

The PV characterizes the degree of lipid oxidation. The PV is affected by storage time as the storage duration increase, the value of PV also increases. PV values increased from an initial point to the end of the storage period. Our present study related to the [39] that report primary oxidation occurs, leading to secondary oxidation. The lipid oxidation caused the rancidity of fish muscle, which is the main reason for fish spoilage. Many researchers indicated a score of peroxide value. The PV below the 4 meq 02/kg, fish, is considered excellent, 5-10 meq 02/kg as good, between 10 and 20 meq 02/kg as accepted for consumption and above 20 meq 02/kg as 'spoiled the fish' [40]. In our result, PV was maximum in the control group (4.32 to 6.81 meq 02/kg) and T1, T2 shown the lower PV throughout the processing period. The present study could be considered excellent PV. However, there were no significant differences in the means of treatment. At the end of storage, the highest PV values were observed in $(T 3, T 4)$, whereas the lowest PV contents were observed in T1 and T2. This work is also similar to [41] who studied the lipid oxidative used to evaluate the potential protective effect on mince of Atlantic horse mackerel in response to olive leaf powder. PV is a primary lipid degradation marker, which showed a gradual increase in horse mackerel during the storage period. Our finding is in opposition to the [42][43] who reported that plant and herb extracts were showed efficient delay lipid oxidation in anchovy during the storage period. However, it can be concluded that sesame oil and rapeseed oil lead to partial inhibition of lipid oxidation.

\section{Oxidant Marker:}


The highest total phenol content in treatment T1, and T2 (sesame oil emulsion) at 0 days were observed than the T3 and T4 (rapeseed oil emulsion) treatment groups. The Control group seemed to have the lowest phenol content. TAC values remain non-significant in the experimental group's throughout the experimental period. Oxidation stability increase with the storage period and antioxidant decrease because it resists the oxidation reaction.

These results indicated that the phenol compounds significantly contributed to sesame and rapeseed oil's antioxidant capacity. A consecutive decrease in phenolic contents was predicted during the storage period ( 0 to 15 days) to reduce the control group's flavonoid contents. Flavonoid content was affected significantly $(P<0.05)$ in all the treatment and the storage time. These results indicated that the phenol compounds had a major contribution to the antioxidant capacity of sesame and rapeseed oil. The antioxidant marker was affected significantly $(P<0.05)$ in all the treatment during processing. These results are similar to [44]. They used olive leaf powder (OLP) added in minced horse mackerel, which significantly increased the antioxidant marker (total phenol, flavonide content and antioxidant capacity) of samples. The treatment treated with OLP showed the higher antioxidant values during the early days of the storage period. Our findings were also similar to [41], who observed significant TP and TAC reductions during the processing. The decrease of antioxidant capacity and flavonoid content increased the level of lipid (PV, FFA) oxidation markers. During oxidation, antioxidants play an essential role in various ways: metal ions, scavenging radicals, and free radicals.

\section{Sensory Evaluation:}

The sensory evaluation of Channa marulius revealed that the nanoemulsion and vacuum packaging had higher sensory scores than the control group. No significant differences were detected among the T1, T2, T3 and T4. Our study was similar to [45] who tested the sensory results of red drum with an interval of 3 days during the storage period. The fish fillets were acceptable for humans when the sensory score reached 4 . When the score of color, odor, flavor, texture and general acceptability of fish samples reached 9 the fish spoilage start and consumers rejected it. A similar result also following [46], who investigate the shelf life of treated ( 6 gingrol) and untreated red drum according to sensory evaluation score. The treated sample gain the best sensory evaluation score; they did not harm the sensory evaluation of fish muscles. Some plant extracts (rosemary, thyme, and green tea) are used for best quality of fish fillets and preservation for a long time without affecting fish's flavor. [47]

\section{Conclusion}

Rapeseed and sesame oil have been investigated as natural antioxidant agents used as persevering agents in the food industry. In our present study, nanoemulsion of vegetable oil and vacuum packing greatly enhanced sensory evaluation of Channa marulius fillets. However, the use of nanoemulsion by using sesame oil and rapeseed oil reduced the oxidation stability and enhanced the antioxidant activity which was effective in enhancing the shelf life of Channa marulius fillets. In short, control treatment could be used for short-term storage of fillets at refrigeration conditions and our study elaborates the 
possibility of the fillets for long-term storage without fillets spoilage by using nanoemulsion to prevent spoilage of fish products. Channa marulius fillets treated with nanoemulsion of sesame oil; showed better results than the rape seed oil however, may be due to the odor's odor, the overall acceptability of filets was less than the rapeseed oil nanoemulsion. According to sensory analysis, control group fish filets were rejected by panelists after a shelf-life of 7 days. Finally, the lipid oxidation parameters showed that sesame oil was the most effective in preventing oxidation in Channa marulius filets.

\section{Abbreviations}

FFA: Free fatty acid, P.V: Per Oxide Value, TAC: Total Antioxidant Activity, TPC: Total Phenol Content, R.O: Rapeseed oil, S.O: Sesame oil.

\section{Declarations}

\section{Consent for publication:}

I, Iqra Anwer give my consent for information about myself to be published in journal lipids in health and disease. LHAD-D-19-00172 Nanoemulsion of Virgin Rapeseed and Sesame Oil improve Oxidation Stability and Sensoric acceptability of Vacuum Packed Fish Fillets.

I understand that the information will be published. This consent form will be submitted with the article and will be treated confidentially. All the given information original.

\section{Availability of data and materials:}

The dataset supporting the conclusion of this article is included within the article

\section{Funding:}

Research has been conducted on the available resources of University of Veterinary and Animal Sciences Lahore, Pakistan

\section{Authors' contributions:}

IA has done the major research work including the bench work, FFA provided guidance for the preparation of nano-emulsion, sensory evaluation. MHR was the supervisor, and has given technical guidance in bench work assisted in thesis and manuscript writing, MN helped out in antioxidant analysis in Channa marulius fish meat samples, help in drafting the manuscript. MK assisted statistical analysis and manuscript writing. MB assisted in research and oxidation analysis. MI helped in sensoric analysis. "It's also confirmed that all the authors read and approved the final manuscript"

\section{Ethics approval and consent to participate}

\section{Statement}


The experiment manipulations and methods are undertaken in compliance with guidelines were approved by ethical reviews committee of University of Veterinary and Animal Sciences Lahore Pakistan. The methods were carried out in accordance with the approved guidelines of the institutional Ethics Committee.

\section{Ethical approval.}

This article does not contain any studies with human participants or animals performed by any of the authors.

\section{Acknowledgement:}

The authors are highly obliged to the Central Laboratory Complex (Food Chemistry) for the access to the sophisticated equipments and Higher Education Commission, (HEC) Islamabad.

\section{Authors' information}

${ }^{1}$ Department of Fisheries and Aquaculture, University of Veterinary and Animal Sciences, Lahore, Pakistan, ${ }^{2}$ Department of Dairy Technology, University of Veterinary and Animal Sciences, Lahore, Pakistan

${ }^{3}$ Department of biological Sciences. Chung Ang University. South korea.

\section{References}

1. Kris E, Harris WS, Appel LJ. Fish consumption fish oilomega-3 fatty acids and cardiovascular disease.;Circulation. 2002106(21):2747- 2757.

2. Hafeez-ur-Rehman M., Ashraf M, Abbas F, Qureshi I A, Mehmood-ul-Hassan M, Iqbal KJ. Abbas S. Effect of Different Doses of Ovaprim (sGnRHa+Domperidone) on the Egg Fecundity and Reproductive Hormone Levels in Channa marulius. Anim. Plant Sci. 2015; 25(6): 1585-1590

3. Shourbela RM, Abd EL, Abd EG.Are Pre Spawning Stressors Affect Reproductive Performance of African Catfish Clariasgariepinus. Turkish J Fish Aquatic Sci. 2016; 16:651-657.

4. Jimenez CF, Salcedo SL, Bou R, Cofrades S, Herrero AM, Ruizm CC. Novel applications of oilstructuring methods as a strategy to improve the fat content of meat products. Trends in Food Sci Tech. 2015; 44(2): 177-188.

5. Salcedo SL, Cofrades S, Ruiz CC, Carballo J, Jimenez CF. Konjac-based oil bulking system for development of improved-lipid pork patties: Technological, microbiological and sensory assessment. Meat Sci. 2015; 101:95-102.

6. Salcedo SL, Cofrades S, Ruiz CC, Jiménez CF. Effect of cooking method on the fatty acid content of reduced-fat and PUFA-enriched pork patties formulated with a konjac-based oil bulking system. Meat Sci. 2014; 98(4),795-803. 
7. Huang D, Boxin OU, Prior RL. The chemistry behind antioxidant capacity assays. J Agri. Food Chem. 2005;53(6): 1841-1856.

8. Paiva MF, Correia R, Felix S, Ferreira P, Gordon MH. Effects of enrichment of refined olive oil with phenolic compounds from olive leaves. J Agri and Food Chem. 2007;55: 4139-4143.

9. Gutteridge JMC, Halliwell, B. Antioxidants: Molecules, medicines, and myths. Biochemical and Biophysical Research Communications. 2010; 393, 561- 564.

10. Cao X, Tsukamoto T, Seki T, Tanaka H.4-Vinyl-2,6-dimethoxyphenol (canolol) suppresses oxidative stress and gastric carcinogenesis in Helicobacter pyloriinfected carcinogen-treated Mongolian gerbils. Int J Cancer. 2008; 122:1445-1454.

11. Vuorela S, Kreander K, Karonen M, Nieminen R. Preclinical evaluation of rapeseed, raspberry, and pine bark phenolics for health related effects. J Agric Food Chem. 2005; 53:5922-5931.

12. Aladedunye F. Natural antioxidants as stabilizers of frying oils. Eurp. J Lipid Sci 2014;116(6): 688706. http://dx.doi.org/ 10.1002/ejlt.201300267.

13. Ladikose D, Lougovoise V. Lipid Oxidation in Muscle Food: A review. Food Chem. 1990; 35: 295-314.

14. Wasowicz E, Gramza A, Heoe M, Jelen HH, Korczak J.Oxidation of Lipids in Food. Pol J Food and Nutr Sci. 2004; 54: 87-100.

15. Serdarglu M, Felekoglu E. Effects of using rosemary extract and onion juice on oxidative stability of sardine (Sardinapilchardus) mince. J Food Quality. 2005; 28: 109-120.

16. Amanatidou A, Schluter O, Lemkau K, Gorris LGM, SmidEJ , Knorr D. Effect of allife of fresh Atlantic salmon.Innovative Food Sci and Emerging Tech. 2000; (1): 87-98.

17. Medina I, Undeland I, Larsson K, Storro I, Rustad T, Jacobsen C. Activity of coffee acid in different fish lipid matrices: A review. Food Chem. 2012;131:730-740.

18. Serdarglu M, Felekoglu E. Effects of using rosemary extract andonion juice on oxidative stability of sardine (Sardinapilchardus) mince. J. Food Quality. 2005; 28: 109-120.

19. Jittinandana S, Kenney PB, Slider SD, Kiser RA.Effect of brining concentration and brining time on quality of smoked rainbow trout fillets. J Food Sci. 2002;67:(6) 2059-2095.

20. Nettles C. Microbial control by packaging: a review.Critical Reviews in Food Sci and Nutr. 2002;42:151-161.

21. Joe MM, Chauhan PS, Bradeeba K, Shagol C, Sivakumaara PK, Sa T. Influence of sunflower oil based nanoemulsion (AUSN-4) on the shelf life and quality of Indo-Pacific king mackerel (Scomberomorus guttatus) steaks stored at 20C. Food Control. 2012; 23: 564-570.

22. McClements DJ, Jafari SM. General aspects of nanoemulsions and their formulation. InNanoemulsions 2018 Jan 1 (pp. 3-20). Academic Press.

23. Official Methods of Analysis of AOCS. 4th ed. Method Cd 8-53. Official Methods and Recommended practices of the American Oil Chemists Society, 4th ed. AOCS, Champaign, IL, USA. 1995.

24. 24Nile SH, Khobragade CN. Antioxidant activity and flavonoid derivatives of Plumbago zeylanica. Journal of Natural Products. 2010;3(16):130-3. 
25. Khanzadi S, Gharibzadeh S, Raoufy M, Razavilar V, Khaksar R, Radmehr B. Application of artificial neural networks to predict Clostridium botulinum growth as a function of Zataria Multiflora essential oil, pH, $\mathrm{NaCl}$, and temperature. Food Safety. 2010;30: 490-495.

26. AOAC. Official methods of analysis, 18th edition. Arlington, VA: Association of Official Analytical Chemists, AOAC Press; 2006.

27. Schanderi SH. Methods in food analysis. New York: Academic; 1970. p. 709.

28. Nabasree D, Bratati D. Antioxidant activity of some leafy vegetables of India: A comparative study. Food Chem. 2007;101: 471-474.

29. 29Meilgaard MC, Civille GV, Carr BT. Sensory Evaluation Techniques. 4. Boca Raton: CRC Press; 2007. p. 464.

30. Codex Alimentarius, 1999. Codex Guidelines for the Sensory Evaluation of Fish and Shellfish in Laboratories CAC-GL31-1999, Training of Assessors. Codex Alimentarius Commission, Rome, pp. 9-16. Add in sensory evaluation.

31. Vanitha M, Dhanapal K, Reddy GVS. Quality changes in fish burger from Catla (Catla Catla) during refrigerated storage. J Food Sci Technol. 2015; 52(3):1766-71.

32. Yerlikaya P, Gokoglu N, Uran H. Quality changes of fish patties produced from anchovy during refrigerated storage. Eur Food Res Technol. 2005; 220(3-4):287-91.

33. Yazgan H. Effects of nanoemulsion based on sunflower oil on sensory, chemical and microbiological quality of sea bass (Dicentrarchuslabrax) and sea bream (Sparusaurata) stored at chilled temperature $\left(2 \pm 2{ }^{\circ} \mathrm{C}\right)$. Ph.D. Thesis Adana, Turkey: Department ofFisheries and Processing Technology, Institute of Natural and Applied Science, CukurovaUniversity. 2013.

34. Ozogul F, KusB, Kuley E. The impact of strawflower and mistletoe extract on quality properties of rainbow troutfillets. InterJ Food Sci Tech. 2013;48:2228-2238.

35. Cao X, Tsukamoto T, Seki T, Tanaka H. 4-Vinyl-2,6-dimethoxyphenol (canolol) suppresses oxidative stress and gastric carcinogenesis in Helicobacter pyloriinfected carcinogen-treated Mongolian gerbils. Int. J. Cancer. 2008; 122:1445-1454.

36. Waraho T, McClements DJ, Decker EA. Impact of free fatty acid concentration and structure on lipid oxidation in oil-in-water emulsions. Food Chem. 2011; 129: 854-859

37. Turhan s, Sagir I, Temiz H.Oxidative stability of brined anchovies (Engraulisencrasicholus) with plant extracts. Inter J. Food SciTechn. 2009;44 386-393.

38. Bensid A, Ucar Y, Bendeddouche B, Ozogul F. Effect of the icing with thyme, oregano and clove extracts on quality parameters of gutted and beheaded anchovy (Engraulisencrasicolus). FoodChem 2014;145:681-686

39. Refsgaard HH, Tsai L, Stadtman ER. Modifications of proteins by polyunsaturated fatty acid peroxidation products. Proceedings of the National Academy of Sciences. 2000;97(2):611-6.

40. Schormüller The chemistry and biochemistry of cheese ripening. Advances in Food Res. 1968;16:231-334. 
41. Sanchez AL, Borderias Technological effect of red grape antioxidant dietary fiber added to minced fish muscle. J Food Sci Tech. 2008;43:1009-1018.

42. Turhan s, Sagir I, Temiz H.Oxidative stability of brined anchovies (Engraulisencrasicholus) with plant extracts. Inter J. Food SciTechn. 2009;44 386-393.

43. Bensid A, Ucar Y, Bendeddouche B, Ozogul F. Effect of the icing with thyme, oregano and clove extracts on quality parameters of gutted and beheaded anchovy (Engraulisencrasicolus). FoodChem 2014;145:681-686.

44. Irene A, Ana B. Martín D, Isabel J, Roberto J, Avena B,Tara H. M, Hugh, Gary R, Takeoka, Lan D, Daniel R.2017.Antioxidant effect of olive leaf powder on fresh Atlantic horse mackerel (Trachurustrachurus) minced muscle.J food proc pres.

45. Fan WJ, Chi YL, Zhang S. The use of a tea polyphenol dip to extend theshelf life of silver carp (Hypophthalmichthys molitrix) during storage in ice. FoodChem. 2008;108:148-153.

46. Li T, Li J, Hu W, Li X. Quality enhancement in refrigerated red drum(Sciaenopsocellatus) fillets using chitosan coatings containing natural preservatives. Food Chem. 2013;138:821-826.

47. Messina CM, Bono G, Renda G, BarberaLL, Santulli A.Effect ofnatural antioxidants and modified atmosphere packaging in preventing lipid oxidation and increasing the shelf-life of common dolphin fish (Coryphaenahippurus)fillets. Food Sci Tech. 2015;62:271-277.

\section{Figures}

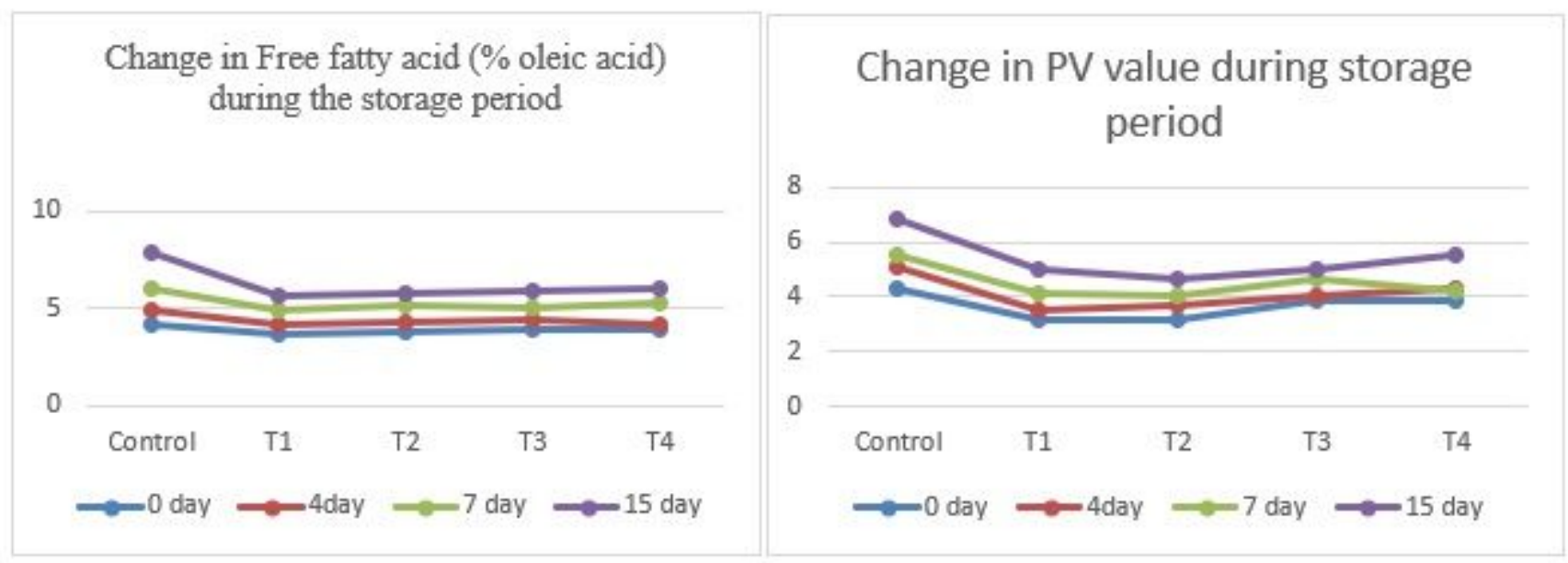

\section{Figure 1}

Change in Oxidation Marker in treatment during the storage period. 


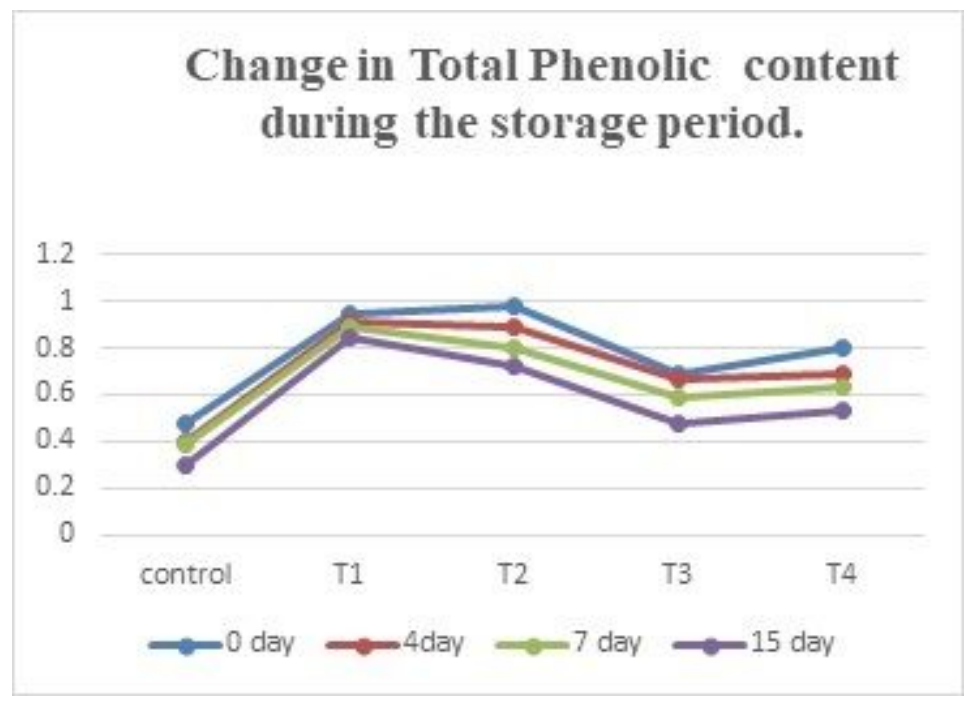

Figure 2

Representing TPC contents among experimental groups

Change in Total flavonoid content during the storage period.

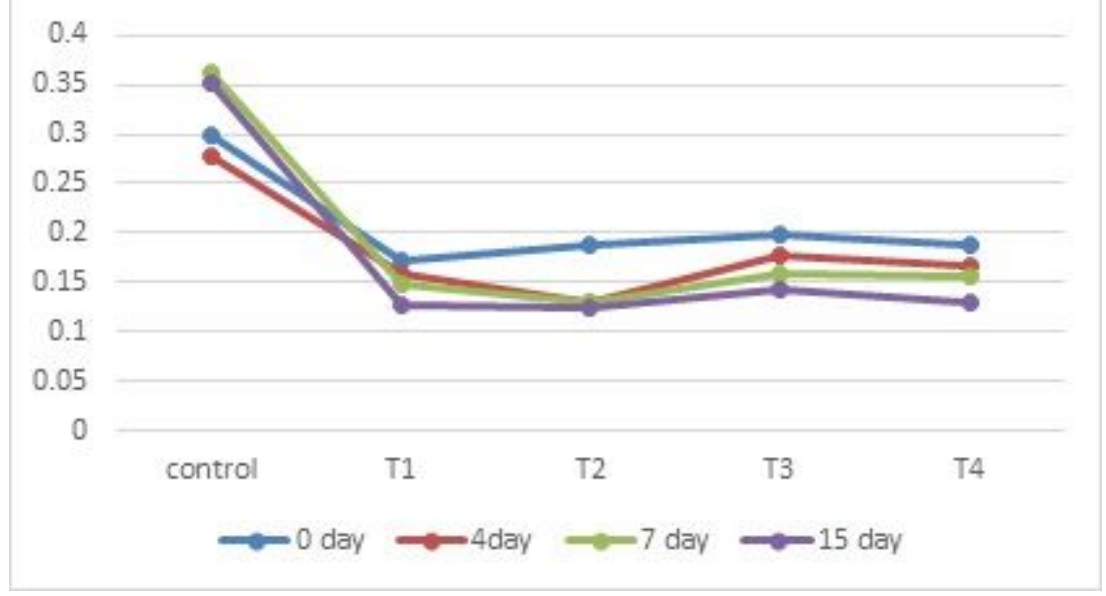

Figure 3

Representing TFC contents among experimental groups 


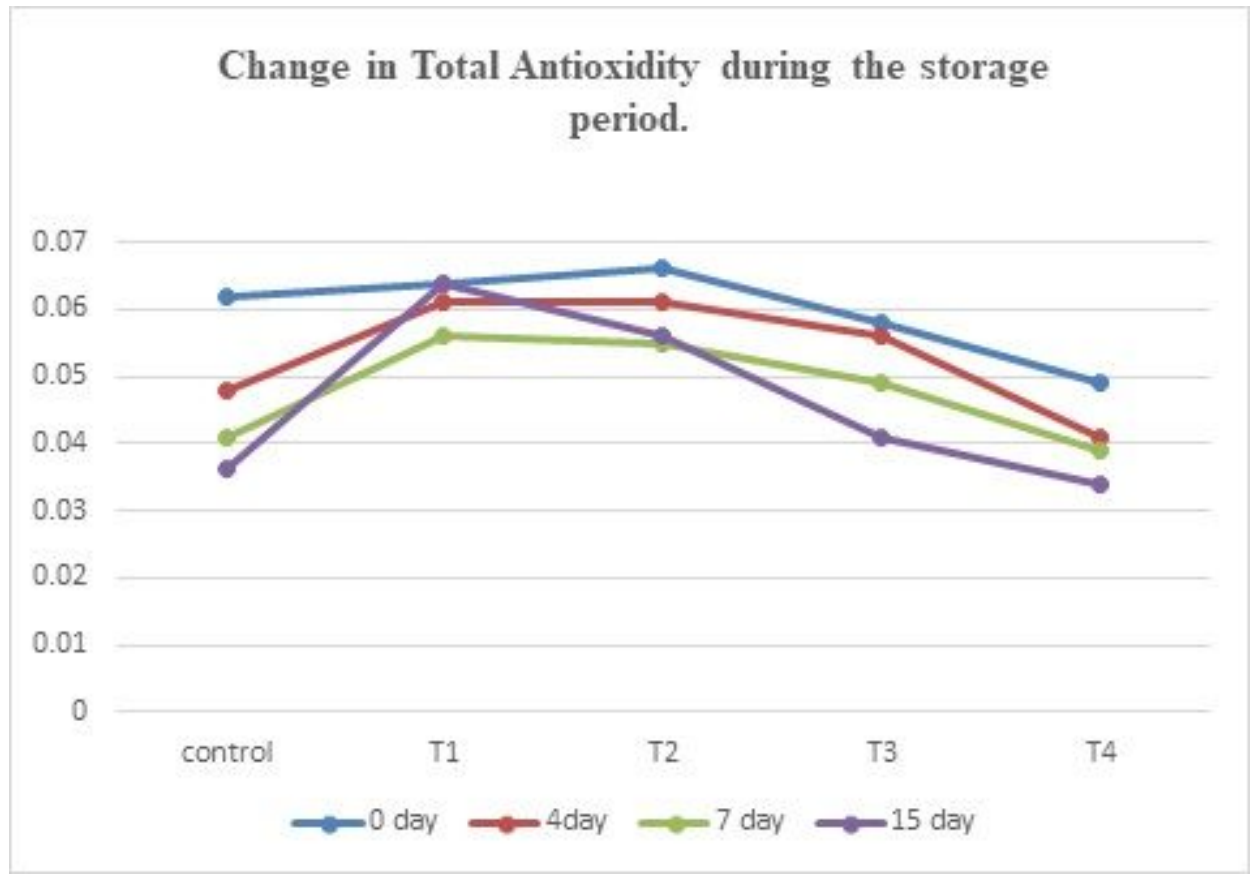

Figure 4

Representing TAA contents among experimental groups 

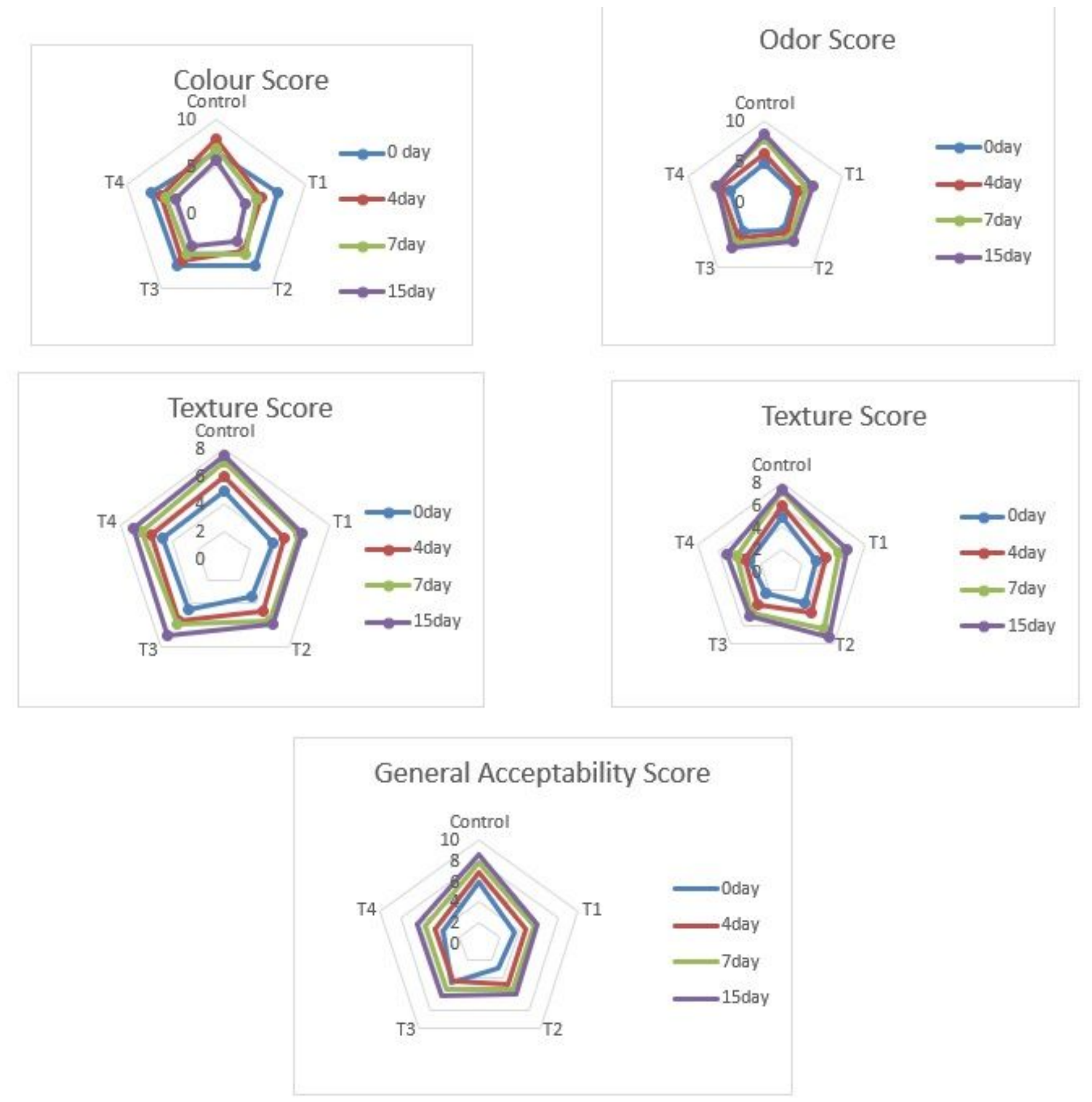

Figure 5

Change in sensory attribute during the storage period in response to different treatment. 